\title{
Cyber physical systems implementation for asset management improvement: A framework for the transition
}

\author{
L. Villar-Fidalgo \\ Universidad Nacional de Educación a Distancia (UNED), Spain
}

\author{
A. Crespo Márquez, V. González Prida, A. De la Fuente, P. Martínez-Galán \& A. Guillén \\ Universidad de Sevilla, Spain
}

\begin{abstract}
The transformation of the industry due to recent technologies introduction is an evolving process whose engines are competitiveness and sustainability, understood in its broadest sense (environmental, economic and social). This process is facing, due to the current state of scientific and technological development, a new challenge yet even more important: the transition from discrete technological solutions that respond to isolated problems, to a global conception where the assets, plant, processes and engineering systems are conceived, designed and operated as an integrated complex unit. This vision is evolving besides a set of concepts that are, in some way, to guide this development: Smart Factories, Cyber-Physical Systems, Factory of the Future or Industry 4.0, are examples. The full integration of the operation and maintenance $(\mathrm{O} \& \mathrm{M})$ processes in the production systems is a key topic within this new paradigm. Not only that, this evolution necessarily results in the emergence of new processes and needs of O\&M, i.e. also, the O\&M will undergo a profound transformation. The transition from actual isolated production assets to such Industry 4.0 with CPS is far from easy. This document presents a proposal to develop such transition adapting one iteration of the Model of Maintenance Management (MMM) integrated into ISO 55000 to the complexity of incorporating "System of Systems" CPSs maintenance. It involves several stages: identification, prioritization, risk management, planning, scheduling, execution, control, and improvement supported by system engineering techniques and agile/concurrent project management.
\end{abstract}

\section{INTRODUCTION}

Cyber-Physical Systems (CPS) is a widespread concept with several meanings, usually linked with embedded and connected systems.

The term cyber-physical systems was coined by Helen Gill in 2006 at the National Science Foundation in the U.S. to refer to the integration of computation with physical processes.

One of the earliest and referred papers describes them as "... are integrations of computation with physical processes. Embedded computers and networks monitor and control the physical processes, usually with feedback loops where physical processes affect computations and vice versa." (E.A. Lee 2008). In the early 2010 's was defined as "transformative technologies for managing interconnected systems between its physical assets and computational capabilities" (Baheti \& Gill 2011). It was a wider definition and avoids any technical description. The most recent release of Framework for CPS released by American National Institute of Standards and Technology (NIST CPS Public Working Group 2017) opens even more the definition: "... are smart systems that include engineered interacting networks of physical and computational components". But simultaneously the technical description needs a complete section -2.1 - of the document, and details in other section -1.1.2 - thirteen main differences with conventional product, system, and application design. This process of increasing the technical description extension while broaden the scope by shrinking the term definition and using vague words, reveals the complexity of these systems.

Despite this complexity, Industry will have to deal with the integration of CPS into their asset portfolio and their maintenance framework. It is a straightforward way to improve their performance in the global and competitive market that they face nowadays. The disruptive aspect of CPS in Operation \& Maintenance of assets are two. The first one is their ability to share information \& self-compare their behavior in an autonomous way as a community of equipment. For example: a network of CPS pumps will be able to predict the failure of one of their members based on shared information, without the intervention of higher level supervisors. The prognostics and health management has an open road ahead. The second disruptive aspect is 
their ability to identify a misuse or improper use by human operators: two conveyor belts could compare themselves and rise a warning if one of them is overloaded while the other is underutilized. Unfortunate ly for maintenance personnel, most of their interventions will be over legacy and operating Systems of Systems interacting with human beings: plant operators, maintenance technicians, etcetera. Their intervention will have also to deal with the seven samurais (Martin 2004) systems: context, intervention, realization, deployed, collaborating, sustainment and competing.

This paper will propose a framework to introduce CPS assets and their philosophy for Operations \& Maintenance in those real environments.

\section{METHOD}

Assuming a company that follows the Maintenance Management Model (Márquez 2007) as a framework for maintenance that fulfills the ISO 55000standard for asset management (Crespo \& Parra 2018). The starting point for CPS integration in the asset portfolio should appear as a decision of phase 8 of an iteration (Continuous improvement and new techniques utilization): The company decision is to adopt the industry 4.0 concepts. In doing so it will implement Cyber-Physical Systems (CPS) as future assets and uplift the existent ones to this concept. Therefore, a new iteration in the complete Maintenance Management Model is proposed $^{1}$. This iteration will also follow the Cyber Physical Framework. The actual target is to achieve the Function III (Cyber level) of the 5C level architecture for implementation of CPS (J. Lee, Bagheri, $\&$ Kao 2015), as a previous step to the full completion (Configuration Level) in future iterations.

It will be analyzed in the next paragraphs the eight phases of Maintenance Management Model as decision areas to implement our strategy regarding the inclusion of CPS in our asset portfolio. There will not be further references to "business as usual" activities of above mentioned framework related to maintenance process of the company.

\section{PHASE 1: DEFINITION OF THE MAINTENANCE OBJECTIVES AND KPI'S}

Along this phase there is a conceptualization facet: the main effort is to obtain the model that will satisfy our requirements under the distinct aspects of

${ }^{1}$ Only the new activities due to CPS are mentioned in the paper. The business as usual activities of the cycle are not included: refer to the original
CPS framework: Functional, Business, Human, Trustworthiness, Timing, Data, Boundaries, Composition and Lifecycle. It is one of the phases deeply impacted by CPS implementation. During this phase, the decisions taken will determine the level I of the 5C architecture: The Smart Connection Level function with Plug \& play, tether-free communication and sensor network as attributes.

Basic tool for this phase is Balanced Scorecard integrating not only economic performance and technical indicators of operation and maintenance but also project execution and Human factors of iteration to integrate CPS in the assets portfolio.

\subsection{Objectives to add}

1. CPS implementation policy. This policy should consider the importance of achieving tangible objectives of CPS as soon as possible, to engage the main stakeholders. So, assets to upgrade/ substitute must be carefully chosen; on later iterations under MMM it can be implemented the fully transformation of portfolio.

2. Maintainability, risk reduction, reliability and availability improvement to achieve by new/ uplifted CPS assets. Obviously, these parameters should be increased above the average.

3. Economic impact of overall operation. Capital expenditure should be considered carefully: In the future, the balance between investment and return obtained will be scrutinized for such technology change and can jeopardize further deployment.

4. Domains of CPS framework implementation should be identified; these are the areas of deployment in which stakeholders may have domain-specific (manufacturing) and crossdomain concerns (Energy, transportation). Groups of conceptually equivalent or related concerns will became the Aspects of the CPS framework of our interest.

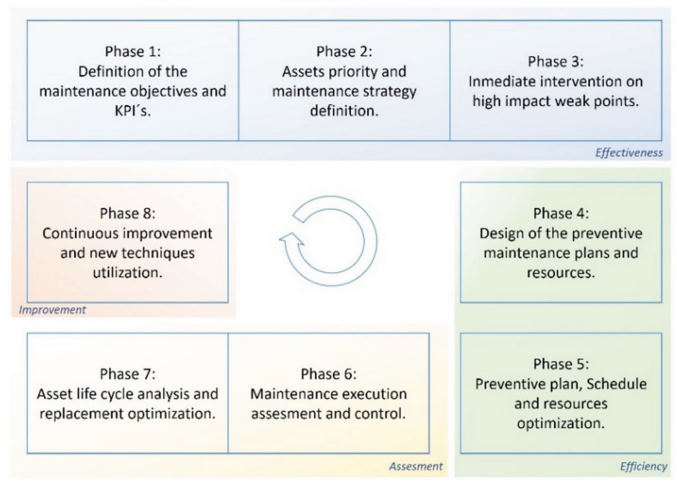

Figure 1. MMM schema. 


\begin{tabular}{|c|c|c|c|c|}
\hline Level & Function & Techniques & Attributes & $\begin{array}{l}\text { System of systems } \\
\text { action level }\end{array}$ \\
\hline $\mathrm{L} 5$ & Configuration & $\begin{array}{l}\text { Resilient Control System } \\
\text { (RCS):Action to avoid }\end{array}$ & $\begin{array}{ll}\text { - } & \text { Self configure for resilience } \\
\text { - } & \text { Self adjust for variation } \\
\text { - } & \text { Self optimize for disturbance }\end{array}$ & \\
\hline L4 & Cognition & $\begin{array}{l}\text { Decision support system } \\
\text { (DSS): Prioritize and } \\
\text { Optimize Decisions }\end{array}$ & $\begin{array}{l}\text { - Integrated simulation and synthesis } \\
\text { - } \quad \text { Remote visualization for human } \\
\text { Collaborative diagnostics and decision } \\
\text { making }\end{array}$ & DECISION \\
\hline L3 & $\begin{array}{l}\text { Cyber Physical } \\
\text { Systems (CPS) }\end{array}$ & Self-Compare & $\begin{array}{l}\text { - Twin model for components and } \\
\text { machines } \\
\text { Time machine for variation identification } \\
\text { and memory } \\
\text { - Clustering for similarity in data mining }\end{array}$ & \multirow{3}{*}{ DATA COLLECT } \\
\hline L2 & $\begin{array}{l}\text { Data to } \\
\text { information } \\
\text { conversion }\end{array}$ & $\begin{array}{l}\text { Prognosis and Health } \\
\text { Management: Self- } \\
\text { Aware }\end{array}$ & $\begin{array}{l}\text { Smart analytics for component machine } \\
\text { health. } \\
\text { - Multi dimensional data correlation } \\
\text { Degradation and performance prediction }\end{array}$ & \\
\hline $\mathrm{L} 1$ & $\begin{array}{l}\text { Smart } \\
\text { connection }\end{array}$ & $\begin{array}{l}\text { Condition Based } \\
\text { Maintenance: Condition } \\
\text { Monitoring }\end{array}$ & $\begin{array}{ll}\text { - } & \text { Plug \& play } \\
\text { - } & \text { Tether-free communication } \\
\text { - } & \text { Sensor network }\end{array}$ & \\
\hline
\end{tabular}

Figure 2. 5C level architecture (Lee et al.).

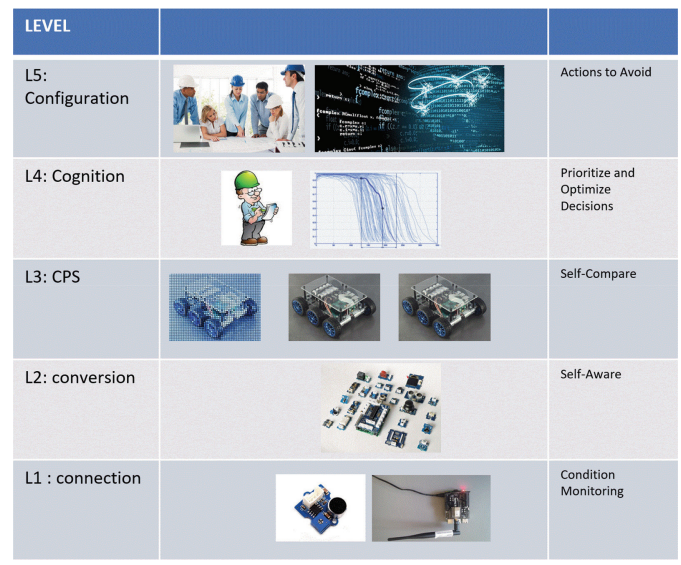

Figure 3. 5c architecture overview examples (Lee et al.).

\subsection{Identify the critical questions to be answered and key decisions to be taken}

1. New Stakeholders identification and documentation of their expectations. Consultants and technology providers are new stakeholders, but it should be also reexamined the old ones with new concerns: maintenance personnel and operators should change their approach to these systems improving their technical skills in software/hardware; it will imply new training. Report processes, command chain and IT systems will be also impacted.
2. Legal \& safety concerns: Due to the recent development of CPS, there is a lack of regulation, but it will have a deep impact in the future for safety or environmental risky systems. The legislation will affect them and their crypto conditions to avoid any unintended access. The CPS framework has a full detailed coverage of this concerns and the assurance facet is described in detail.

3. Technological state of the art. Due to the lack of maturity, it must be evaluated which technologies will survive in a few years. Open standards will help to survive or, at least, to ease the transition to new ones in the future.

4. Identify leaders (internal and external) for new know-how transference and acquisition.

5. Other Standard, Policies, Directives and Procedures to be adapted. It has been mentioned the technological ones, but other business domains should be also considered. As an example: CPS themselves could inform of earned value to the project management software (units produced, finish of testing phase, finish of startup process...)

6. Cyber-level infrastructure and Machine-cyber interface.

7. ERP and Enterprise Asset Management software data flow impact.

8. Big data analysis systems and AI deployment.

9. Training of personnel.

10. Infrastructures, Special tools and test equipment needed or affected.

IT infrastructures play a key role in CPS systems. So, critical questions must be faced in this 
stage as a decision-making breakdown structure for IT to be implemented in the CPS:

In the software level, the continuous evolution of information technologies is a risk factor and the use of open and standard methodologies for communications, like REST APIs with HATEOAS to exchange data, based on JSON or XML should be a priority. A wrong step in this direction could endanger the rest of the project by making CPS unable to communicate among them.

Regarding physical layers of communications (wired or wireless) it should be followed the same principle: looking for standard and open technologies. Of course, wired TCP/IP should be there, but wireless technologies are here to stay, and it is far more confusing the election:

Low-rate wireless personal area networks under IEEE 802.15.x or WIFI could be a reasonable decision for locally deployed systems.

For wide areas, it could be chosen between licensed LPWA technologies standardized by 3 GPP (EC-GSM-IoT, LTE MTC Cat M1 and NB-IoT) or other commercial LPWA solutions: LoRAWAN or SigFox. These are closed technologies.

The future would pass through commercial $5 \mathrm{G}$ bands categorized into three generic services, namely, extreme mobile broadband, massive machine-type communications, and ultra-reliable machine-type communications.

\subsection{KPIs}

1. Human factors: strong leadership is needed, to overcome resistance and barriers, to change mindsets, to push through organizational change, to sustain investment, and to keep the team involved, specifically during the transition. Indicators over these soft factors will help to measure the pulse of the organization. It is important because the benefits of the CPS will appear after the integration of some of them: at the beginning of the process, only problems will arrive without any apparent benefit.

2. Speed of update in infrastructures, assets, etcetera: transition should be implemented fast enough to achieve evident benefits during the first stages, but avoiding over stress the organization (shutdown and start up production, new training, new processes, etcetera)

3. AI transition and assets peer to peer comparison. As one of the theoretically most disruptive changes that brings CPS, we should monitor the efficiency of this behavior through the economic impact in our organization. Installing only a modern gadget will fail as objective.

4. Earned Value management indicators (EV, CPI, SPI) are a good reference for any project to deploy CPS. It should also use the American Defense Contract Management Agency 14 points of Baseline Execution Index for planning and schedule. These are objective indicators of project's financial status, as one of the main concerns of the enterprise.

\subsection{Audits}

The use of audits will have two variants: the ones for control and continuous improvement according to MMM (MES, QMEM, etcetera) and specific ones to check the efficiency and effectivity of CPS implementation. These audits should focus on the incremental evolution of CPS upgrade: The added value of firsts units implemented should be audited against their objectives.

\section{PHASE 2: ASSETS PRIORITY AND MAINTENANCE STRATEGY DEFINITION}

Basic tool is Criticality Analysis, upgraded to include the risk of project-failure during implementation of CPS: It is needed to prioritize those assets with higher Return on Investment and lower technical risks. During the first iteration one of the highest risks is disaffection of CPS by main stakeholders. So, the asset to be upgraded at this early stage should be with high improvement-visibility, affordable capital expenditures effort, lower technological risk, easy to O\&M in the near future.

\subsection{Determination of actions on actual assets based on risk factor analysis to:}

1. Replace/substitute for a new asset.

2. Uplift and improve the existent ones.

It will be scored using the concerns of CPSFWK tailored accordingly. Without been exhaustive, in this first iteration it should be paid special attention to several concerns enumerated in the framework:

1. Functional: monitorability and communication.

2. Business: cost, time to market, utility and interoperability.

3. Timing: awareness and resilient time.

4. Boundaries: networkability, responsibility.

5. Composition: adaptability, constructivity and discoverability.

6. Lifecycle: procureability, deployability and mantenability.

7. Human: usability.

8. Trustworthiness: safety, reliability and cybersecurity.

These are, under author considerations, the key aspects to assure stakeholders engagement during the first iteration. 
4.2 Planning and scheduling to retrofit the assets. Based on the CPS 5 C level architecture, with target of cyber level

It will be used turnaround, shutdown and Outage operations to implement the new CPS assets or transform the legacy ones in CPS systems.

The authors recommend using Kanban agile practices embedded in a general schedule (Villar-Fidalgo, Espinosa-Escudero \& DomínguezSomonte 2016 \& 2017), according to PMI ${ }^{\circledR}$ Agile Practice Guide (2017). The "product owner" value team might produce a roadmap to show the anticipated sequence of CPS to add or legacy systems to upgrade over the time. This planning will include conceptual, preliminary and detailed design, development, construction, $\mathrm{M} \& \mathrm{O}$ and disposal phases. This team re-plans the roadmap based on what the results are.

Due to the complexity of the CPS concept and lack of maturity, incremental and iterative changes during several iterations are preferable than a complete transformation in a single endeavor with waterfall planning and scheduling. Besides the intrinsic resilience and flexibility of a welldesigned CPS will benefit this approach.

Agile-lean Kanban Method fits perfectly in particular steps of the proposal: Starts with current state, it is incremental, respects the current process, roles, responsibilities and titles. It will help dealing with overcoming requirements

The main adversary is that enterprise culture not always embrace leadership attitude at all levels.

\subsection{EV baseline evaluation}

This baseline will help to measure the performance of transition. The variances over baseline estimations will identify the need of upgrade the plan or maintain the initial target. Deviations off the baseline will not only affect the financial performance of the transition project but also stakeholder's engagement with CPS vision.

\section{PHASE 3: IMMEDIATE INTERVENTION ON HIGH IMPACT WEAK POINTS}

Basic tool is Failure Root Cause Analysis (FRCA), to look for high impact reliability enhancements and ensure a very effective definition of subsequent maintenance plan activities. Adding a new cause of failure is necessary, as it is recognized in CPS framework aspect of trustworthiness, based on security, privacy, safety, reliability and resilience of future CPS. The high complexity of network based software is a new factor to consider in the FRCA analysis over traditional physical, human and latent causes inherent to any kind of systems.
Nevertheless, it should be also intervened in high impact favorable assets to CPS transformation: those items which could lead to enhance the visibility of CPS advantages. A key reactor of high economical value deems for sure to be upgraded to CPS level, but their actual monitorization as a single asset with conventional SCADA and PLCs plugged to the network will dilute the improvement of such upgrade. On the other hand, a set of water flow pumps will not be as spectacular as the reactor, but their number and failure rate could make them ideal candidates to be upgraded if it is possible to achieve some good failure prognostics based on their shared data, including condition based on sensors and usage rate.

\subsection{Retrofit of highest priority assets to CPS level in first incremental iterations of schedule}

The priority will be based on:

1. Affordability of implementation and economic benefit for asset exploitation.

Feasibility of full CPS application.

Trustworthiness of implementation.

Visibility of CPS enhancements.

\subsection{Data capture and data mining to extract the information, probably under "big data" considerations}

The first data extracted and initial behavior of CPS itself should follow the planned strategy. Otherwise will be necessary to adapt, preferably through agile methodologies, the next steps.

It should be achieved the maximum net benefits per system replaced/upgraded during the earliest stages of implementation, because of the priority criteria used. If the results are not the expected, it is an alarm signal that should draw attention to strategy or, at least, re-plan the implantation priorities. During this phase, it should be achieved the $5 \mathrm{C}$ architecture function 2: Data - to information Conversion Level. The attributes are smart analytics for component machine health with multi-dimensional data correlation and finally the degradation and performance prediction.

\section{PHASE 4: DESIGN OF THE PREVENTIVE MAINTENANCE PLANS AND RESOURCES}

Basic tool is Reliability Centered Maintenance: where operations and maintenance start to be influenced by CPS, depending on the level assigned in the risk plan and within the operational mode. It is far from the function 5 of $5 \mathrm{C}$ architecture: Configuration Level, with attributes of self-X of the 
CPS, but it has information that, supported by new plans and their optimization, will take it to desired Function III of 5C architecture: the cyber level.

After implementation, the maintenance plan should be oriented to Condition Based Maintenance/Prognostic Health Management to exploit all the advantages of CPS. The CPS will probably rise overcoming requirements due to higher precision in sensors and data analysis (big data, M2M peer review), that will fine tune the detection of catastrophic failures. But this fine tune detection will increase the need of fast actuation: it will not only detect the normal worn of a friction bushing but the fast failure of an axle due to unexpected fatigue because of micro cracks (that CPS could infer due to misuse of the asset). The maintenance plans should also embrace the Agile philosophy.

\section{PHASE 5: PREVENTIVE PLAN, SCHEDULES AND RESOURCES OPTIMIZATION}

Basic tool is Risk-Cost Optimization considering the new opportunities that CPS brings. Use of self-compare behavior and machine to machine data exchange (peer monitoring) to identify the state of the asset portfolio and accuracy prognosis will allow to take advantage of dynamic planning and scheduling forecasting with optimal allocation of resources for maintenance and operation. The capacity of CPS to identify misuse or workloads unbalanced will also affect the production plans or operators training plans.

Again, the agile methodologies imbricated in high-level integrated master plan is a must: it should be ready to deal with overcoming requirements that need to be addressed on line. Baseline updates with a transition from original contour conditions (or "samurais") to updated ones will allow to measure performance without losing contact with the new reality. This way audits will continue delivering value.

\section{PHASE 6: MAINTENANCE EXECUTION ASSESSMENT AND CONTROL}

Basic tool is Operational Reliability Analysis, but it should not be forgotten specific aspects of transition phase: under a project environment with highrisk technological transition.

All the KPIs defined in phase 1 will help to control the evolution of the project and the impact in O\&M operations:

1. Measurement, analysis and evaluation of earned value indicators for asset retrofit and start-up: cost and schedule through CPI, SPI,
S-curves and Integrated Program Management Report.

2. Evaluation of indicators of actual performance in reliability, maintainability and future improvement based not only on probabilistic assessments, but also on truthful information and prognostics delivered by new CPS.

3. Evaluation of Risk with cost/benefit evaluation of mitigation plans.

4. CPS transition-speed and acceptance among stakeholders.

Finally, it will be needed to control the improvement achieved with CPS already installed. If we are not able to follow the baseline technical-plan, it should be reconsidered the overall project.

\section{PHASE 7: ASSET LIFE CYCLE ANALYSIS AND REPLACEMENT OPTIMIZATION}

This phase, as the first one, is deeply impacted by CPS. Basic tool is Life Cycle Cost Analysis, but it must include all the facets that new systems will bring to the asset portfolio.

It will face new cost-categories: software upgrades, trustworthiness analysis and developments, data networks deployment and maintenance, etcetera. Nevertheless, it can also achieve important savings: better use of systems by operators, higher accuracy in prognosis maintenance, lower supervision costs due to the "self-awareness" of CPS groups. Unfortunately, this kind of improvement will become very often incomputable because the traditional life cycle analysis has not included these factors. The maintenance team will have to struggle against skepticism to show the advantages of the CPS. This is one of the reasons to make key decisions and answer critical questions during the first phase: once the iteration is at this point, it should have evidences from CPS deployed to support the benefits to Life Cycle Cost, otherwise there will be only important capital expenditures and intangible benefits that could lead to disaffection of critical stakeholders like CFO's.

Another key aspect to highlight is the improvement in risk management and "probability/risk number" of CPS systems, due to a better knowledge of their health as a system.

\section{PHASE 8: CONTINUOUS IMPROVEMENT AND NEW TECHNIQUES UTILIZATION}

It will be necessary to analyze the targets from phase 1 achieved in the concluded iteration. If the result is satisfactory there will have two roads ahead: spread the CPS architecture to more assets or take another step with actual CPS towards 
Function IV of CPS architecture: The Cognition Level. Probably the wisest decision in these times of technological immaturity is spread the CPS concept and study lessons learnt during the first iteration to smooth the continuous uplift / renovation of our asset portfolio.

The Function IV (Cognition Level) and V (Configuration Level) of 5C architecture have an intrinsic high degree of technological uncertainty that make them too risky under the engagement of main stakeholders. They should go through a System Integration Laboratory or prototype phase before the full integration in production assets.

\section{DISCUSION}

The architecture developed by Lee et al. (J. Lee et al. 2015) or the Framework released by NIST (NIST CPS Public Working Group 2017) are clear starting points for deployment of CPS in manufacturing industries. Nevertheless, these documents are focused on the CPS itself.

Our approach is a complementary and holistic view of the CPS implementation in a dynamic environment like the active enterprise. The Human Factor is a cornerstone during business transformation and should be included in the equation.

Another intended contribution is the necessary link between the sequential workflow of construction of a CPS with the iteration phases of the maintenance model and business itself.

\section{CONCLUSIONS AND FURTHER DEVELOPMENT}

This paper presents a framework to incorporate CPS, up to Function 3 of $5 \mathrm{C}$ architecture, in our asset portfolio with a holistic view and under a consolidated maintenance management model. The objective is to avoid early failures that discourage stakeholders from supporting this technology after the first iteration.

This work will continue with use cases evaluation and further iterations to achieve the Function V (Configuration Level) where all the advantages of CPS could be exploited in benefit of maintenance of full assets portfolio, and therefore the business objectives.

\section{REFERENCES}

Agile Practice Guide.2017. Global Standard ed. 14 Campus Boulevard. Newton Square, Penssylvania 19073-3299 USA: Project Management Institute.

Baheti, Radhakisan and Helen Gill. 2011. "Cyber-Physical Systems." The Impact of Control Technology 12: 161-166.

Crespo Márquez, Adolfo and C. Parra Márquez. 2018. "On the Family of Standards UNE-ISO 55000 and how to Effectively Manage Assets." In Advanced Maintenance Modelling for Asset Management, edited by A.Crespo Márquez et al., 1-16: Springer International Publishing AG.

Lee, Edward A. 2008. "Cyber Physical Systems: Design Challenges.", Object oriented real-time distributed computing (isorc), 2008 11th IEEE international symposium on.

Lee, Jay, Behrad Bagheri, and Hung-An Kao. 2015. "A Cyber-Physical Systems Architecture for Industry 4.0Based Manufacturing Systems." Manufacturing Letters 3 (Supplement C): 18-23. doi:https://doi.org/10.1016/j. mfglet.2014.12.001.

Martin, James N. 2004. "The Seven Samurai of Systems Engineering: Dealing with the Complexity of 7 Interrelated Systems. Proceedings of 14th Annual Symposium of the International Council on Systems Engineering." Toulouse, France.

Márquez, Adolfo Crespo. 2007. The Maintenance Management Framework: Models and Methods for Complex Systems Maintenance Springer Science \& Business Media.

NIST CPS Public Working Group. "CPS PWG CyberPhysical Systems (CPS) Framework Release 1.0.", https://pages.nist.gov/cpspwg/.

Villar-Fidalgo, Luis, M. Mar Espinosa-Escudero, and Manuel Domínguez-Somonte. 2016. "Cronogramas Para Toma De Decisiones Ágiles En Entornos Concurrentes Con Incertidumbre." Dyna Management Vol 2017.

Villar-Fidalgo, Luis, Manuel Domínguez Somonte, and María Espinosa Escudero. 2017. "La Gestión Ágil Y Concurrente De Proyectos Con Incertidumbre." Dyna Ingenieria E Industria 92: 16-17. 